\title{
Emprego de polímeros na qualidade tecnológica de grãos de feijão sob condições de armazenamento
}

\section{Use of polymers in the technological quality of beans grains under store conditions}

\author{
Juliano Garcia Bertoldo ${ }^{1 *}$; Jefferson Luís Meirelles Coimbra ${ }^{2}$; \\ Leiri Daiane Barili'3; Naine Martins do Vale*; Marlon Mathias Dacal Coan ${ }^{5}$; \\ Aline Fernandes de Oliveira ${ }^{6}$; Valdir Soldi ${ }^{7}$
}

\section{Resumo}

O objetivo desse trabalho foi avaliar o caráter tempo de cocção em genótipos de feijão recobertos com polímeros ao longo do tempo de armazenamento. O experimento foi conduzido em Lages, Santa Catarina, sendo utilizadas sementes de feijão obtidas da safra 2006/07. O delineamento foi o de blocos ao acaso, com três repetições num esquema fatorial 2 × 3 x 3 (dois genótipos - Pérola e IPR-Uirapuru; três tempos de armazenamento - 0, 45 e 90 dias e; três tipos de recobrimento - sem recobrimento (testemunha), Carboximetilcelulose (CMC) e uma mistura de polímeros na proporção 50/50 de Carboximetilcelulose e Alginato de sódio (CMC-AS). Foi realizada a avaliação do cozimento dos grãos com o uso do aparelho cozedor de Mattson, adaptado por Proctor e Watts (1987). Os resultados indicam um aumento gradativo no tempo de cocção dos grãos de feijão ao longo do armazenamento. Foi possível verificar comportamentos diferenciados entre genótipos $x$ polímeros $x$ armazenamento. O recobrimento com o polímero Carboximetilcelulose para o genótipo Pérola reduz significativamente o tempo de cocção durante o armazenamento. A peletização dos grãos do genótipo Pérola com a mistura dos polímeros na proporção 50/50 de Carboximetilcelulose e Alginato de sódio promove menor variação no caráter tempo de cocção ao longo do armazenamento.

Palavras-chave: Phaseolus vulgaris L, carboximetilcelulose, alginato de sódio, cocção

\footnotetext{
Abstract

The objective of this work was to evaluate the time of cooking of beans genotypes recovered with polymers throughout the storage time. The experiment was carried out in Lages, Santa Catarina, in which were used grains obtained from the 2006/07 harvest. It was used the complete randomized block

${ }^{1}$ Biólogo, Doutorando em Recursos Genéticos Vegetais, Universidade Federal de Santa Catarina, UFSC, Florianópolis, SC. E-mail: jgbertoldo@gmail.com

2 Eng $^{\circ}$. Agr, Dr. Professor da Universidade do Estado de Santa Catarina, Centro de Ciências Agroveterinárias, CAV, Instituto de Melhoramento e Genética Molecular, IMEGEM, Lages-SC. E-mail: coimbrajefferson@cav.udesc.br

${ }^{3}$ Eng $^{\circ}$ Agr $^{\mathrm{a}}$, Mestranda em Produção Vegetal, Universidade do Estado de Santa Catarina, Centro de Ciências Agroveterinárias (CAV), Instituto de Melhoramento e Genética Molecular, IMEGEM, Lages-SC. E-mail: leyridaiana@hotmail.com

${ }^{4}$ Eng $^{\circ}$ Agra ${ }^{a}$, Mestranda em Produção Vegetal, Universidade do Estado de Santa Catarina, Centro de Ciências Agroveterinárias CAV, Instituto de Melhoramento e Genética Molecular, IMEGEM, Lages-SC. E-mail: nainemartinsdovale@hotmail.com

${ }^{5}$ Graduando em Agronomia, Universidade do Estado de Santa Catarina, Centro de Ciências Agroveterinárias, CAV, Instituto de Melhoramento e Genética Molecular, IMEGEM, Lages-SC. E-mail: marloncoan@gmail.com

${ }^{6}$ Dra. Depto. Química, Universidade Federal de Santa Catarina, UFSC, Campus Universitário, Florianópolis, SC. E-mail: line@ qmc.ufsc.br

7 Dr. Professor da Universidade Federal de Santa Catarina, UFSC, Campus Universitário, Florianópolis, SC. E-mail: vsoldi@qmc. ufsc.br

* Autor para correspondência
} 
design with three replications in an $2 \times 3 \times 3$ factorial arrangemente (two genotypes - Pérola and IPR-Uirapuru; three times of storage - 0, 45 and 90 days and; three covered type - without recovered (standard), Carboximetilcelulose (CMC) and a blend (50/50) of Carboximetilcelulose and Alginato of sodium (MCM-AS). The cooking parameters were evaluated by using the Mattson cooker, adapted by Proctor e Watts (1987). There was a gradual increase in the time of cooking of the beans grains with increases on the storage time. There were differentiated behaviors among genotypes x polymers $\mathrm{x}$ storage time. Covering the genotype Pérola with the Carboximetilcelulose polymer reduces the cooking time during the storage. Covering the grains of the genotype Pérola with the blend of polymers Carboximetilcelulose and Alginato of sodium significant decreases the variation of the cooking time throughout the storage.

Key words: Phaseolus vulgaris L, carboximetilcelulose, alginato of sodium, cooking

\section{Introdução}

O feijão é, atualmente, um dos produtos de maior importância agrícola no Brasil. Nos anos de 1975 e 2005, as produções de feijão em grão foram, respectivamente, de 2,28 milhões e 3,08 milhões de toneladas, com uma média de 2,54 milhões de toneladas no período (FAO, 2006). Segundo Ferreira, Del Peloso e Faria (2002) a produção mundial de feijão vem crescendo progressivamente desde os anos 60, onde no início da década de 80 alcançou cerca de 15 milhões de toneladas e desde o seu final passou a oscilar em torno de 16 milhões de toneladas. Segundo dados do IBGE (2009), na safra total do ano de 2009 , a produção foi de 3.478 .775 toneladas apresentando um aumento de $0.5 \% \mathrm{em}$ comparação à obtida no ano anterior (3.460.067) toneladas. Entretanto mudanças no cotidiano dos consumidores propiciaram uma redução no consumo de feijão, de modo que, pode ser verificada acentuada queda no consumo, sendo aos poucos substituído por outros alimentos de menores preços, como frango, macarrão, iogurtes, cereais matinais, leite longa vida, todos de rápido preparo (FERREIRA; DEL PELOSO; FARIA, 2002).

Nessesentido, amelhorianospadrões dequalidade tecnológica do feijão pode auxiliar a reverter esse quadro. Com relação à qualidade culinária, é interessante buscar novas cultivares com redução no tempo de cozimento dos grãos, uma vez que, além de sua importância econômica, o feijão constitui um dos alimentos básicos da população brasileira. Um dos principais fatores na adoção de uma cultivar de feijão pelos consumidores e, conseqüentemente, pelos agricultores, está relacionado ao tempo de cocção, isso porque a maioria das donas de casa tem atividades fora do lar e o tempo disponível no preparo das refeições é cada vez menor (COSTA; RAMALHO; ABREU, 2001). Ainda, a identificação de linhagens com menor tempo de cozimento, rápida capacidade de hidratação, com tegumentos que não se partam durante o cozimento e com alta expansão volumétrica, após o cozimento, é desejável (CARBONELL; CARVALHO; PEREIRA, 2003). Além disso, para o registro de uma nova cultivar de feijão junto ao Serviço Nacional de Proteção de Cultivares (SNPC), do Ministério da Agricultura e Produção Agropecuária (MAPA, 1997), é exigida a avaliação do caráter tempo de cozimento. Todos esses fatores demonstram a importância de se buscar, num programa de melhoramento, a redução do caráter tempo de cozimento.

Devido ao fato dos grãos de feijão serem muito suscetíveis ao armazenamento prolongado, o que promove mudanças estruturais e fisiológicas nos grãos, há um maior dispêndio de tempo necessário para o seu cozimento, de modo que, metodologias de conservação do produto final devem ser avaliadas, no sentido de minimizar tais efeitos negativos. Assim sendo, procurando viabilizar a melhoria nas qualidades tecnológicas do feijão, entre essas a redução no tempo necessário para o cozimento em função do armazenamento prolongado, algumas metodologias alternativas podem propiciar tal mudança, como por exemplo, o recobrimento dos grãos com polímeros. O principal objetivo do 
recobrimento do grão é melhorar o comportamento, tanto do ponto de vista fisiológico, como econômico (OLIVEIRA et al., 2003). Assim, nos últimos anos, o tratamento químico de grãos que utiliza o revestimento compolímeros tem recebidoatençãoem algumas culturas de expressão econômica (PIRES; BRAGANTINI, 2004). Entre essas culturas está o feijão, onde segundo Ni e Biddle (2001), o polímero é principalmente usado em espécies suscetíveis ao frio, como feijão, algodão, soja e milho.

Apesar do aumento na utilização de grãos recobertos foram verificadas nos últimos anos, poucas informações estão disponíveis na literatura sobre o comportamento de grãos recobertos durante o período de armazenamento. Segundo Roos e Moore (1975), para a conservação de grãos cujos recobrimentos sejam mais hidrofílicos, é necessário que estes estejam revestidos primeiramente por materiais impermeáveis, como forma de prevenir a absorção de umidade durante o armazenamento.

Desta forma, o objetivo deste trabalho foi avaliar o caráter tempo de cocção em genótipos de feijão recobertos com diferentes polímeros ao longo do tempo armazenamento.

\section{Material e Métodos}

O experimento foi conduzido na área experimental do Instituto de Melhoramento e Genética Molecular da Universidade do Estado de Santa Catarina (IMEGEM/UDESC), Lages, SC, situada a $27^{\circ} 47^{\prime} \mathrm{S}$ de latitude, $50^{\circ} 18^{\prime} \mathrm{W}$ de longitude e 900 metros de altitude, na safra de 2006/07. A densidade de semeadura foi de 200.000 plantas por hectare. A unidade experimental foi constituída por seis fileiras de $5 \times 3 \mathrm{~m}$ de comprimento, espaçadas em $0,5 \mathrm{~m}$, e com área útil de $12 \mathrm{~m}^{2}$ por parcela.

Os grãos foram cultivados a campo, em parcelas individuais sob delineamento experimental de blocos ao acaso com três repetições por tratamento. Os tratos culturais, como controle de pragas e plantas invasoras, foram realizados sempre que necessário, de maneira que a cultura não sofresse competição. A colheita manual e a trilha das plantas foram realizadas em Janeiro de 2007, e após a separação das impurezas em peneira, os grãos foram secos em estufa a $26^{\circ} \mathrm{C}$ durante 3 dias, até atingirem umidade menor que $12 \%$.

$\mathrm{O}$ experimento de cocção foi conduzido nas dependências do IMEGEM/UDESC, Lages, SC, sendo utilizados grãos de feijão obtidos da safra 2006/07 na área experimental do mesmo local. O delineamento foi o de blocos ao acaso, com três repetições num esquema fatorial $2 \times 3 \times 3$ (dois genótipos, três tempos de armazenamento e três tipos de recobrimentos).

Os genótipos utilizados foram dois cultivares comerciais registrados no Serviço Nacional de Proteção de Cultivares, sendo um do grupo carioca (Pérola) e outro do grupo preto (IPR-Uirapuru). Os genótipos foram armazenados em condições de variação natural da temperatura e da umidade relativa durante o período de zero, 45 e 90 dias após a colheita.

O processo de recobrimento de grãos de feijão foi realizado para as soluções formadoras de filmes nas composições Carboximetilcelulose (CMC) e Alginato de sódio (AS): 100/0, 50/50 (ou seja, uma solução de CMC puro e uma mistura de CMC-AS na proporção 50/50), com uma concentração total de $2 \%(\mathrm{~m} / \mathrm{v})$ e mais os grãos sem recobrimento, empregado como testemunha. Quantidades de polímeros nas composições citadas anteriormente foram pesadas e solubilizadas em água destilada. Após a agitação da solução filmogênica por 24 horas, os grãos foram recobertos. Foram utilizados em média cerca de $1 \mathrm{~mL}$ de solução polimérica para cada 100 sementes. Depois de recobertos, os grãos foram secos em estufa com circulação de ar a uma temperatura de $35^{\circ} \mathrm{C}$. Após secagem os grãos foram armazenados em sacos de papel sob temperatura e umidades de ambiente durante 45 e 90 dias. Os grãos recobertos foram classificados de acordo com o tratamento de recobrimento utilizado, tendo como 
denominações, CMC, CMC-AS os grãos recobertos com os filmes nas composições CMC-AS: 100/0, $50 / 50$, respectivamente.

O modelo estatístico utilizado neste experimento foi:

$y_{i j k l}=\mu+b_{i}+g_{j}+a_{k}+r_{l}+g a_{j k}+g r_{j l}+a r_{k l}+g a r_{j k l}+e_{i j k l}$

para $i=1,, \mathrm{I} ; \mathrm{j}=1, \mathrm{~J} ; \mathrm{k}=1, \mathrm{~K} ; \mathrm{l}=1,, \mathrm{~L}$. Onde $y_{i j k l}$ é o valor observado, referente ao nível $i$ do bloco, combinado com o nível $j$ do fator genótipo, combinado com o nível $k$ do fator armazenamento e com o nível $l$ do fator recobrimento; $\mu$ é o efeito da média geral; $b_{i}$ efeito do bloco $i$ onde se encontra a parcela; $g_{j}$ efeito do nível $j$ do fator genótipo; $a_{k}$ efeito do nível $k$ do fator armazenamento; $r_{l}$ efeito do nível $l$ do fator recobrimento; $g a_{j k}$ é efeito da interação genótipo com armazenamento; $g r_{j l}$ é efeito da interação genótipo com recobrimento; $a r_{k l}$ é efeito da interação armazenamento com recobrimento; $g a r_{j k l}$ é efeito da interação genótipo com armazenamento com recobrimento; $e_{i j k l}$ é o erro experimental associado a yijkle ambos considerados independentes e identicamente distribuídos, com distribuição $\mathrm{N}\left(0, \sigma^{2}\right)$. Como este ensaio não possui um número de repetições constantes (fatorial desbalanceado) foi selecionada a soma de quadrados mais indicada conforme Coimbra et al. (2006).

Para determinar o tempo de hidratação, foi utilizada a metodologia proposta por Morris e Oslon (1950), sendo colocados $16 \mathrm{~g}$ de grãos de feijão em erlenmeyers, e adicionado $100 \mathrm{~mL}$ de água ultra pura MilliQ, à temperatura de $25^{\circ} \mathrm{C}$, em três repetições. Após uma hora, realizou-se a leitura do volume de água não absorvido pelo grão, bem como o peso dos grãos, e assim sucessivamente até as amostras estabilizarem. Após o tempo de embebição, foi realizada a avaliação do cozimento dos grãos com o uso do aparelho cozedor de Mattson, adaptado por Proctor e Watts (1987). O aparelho é constituído por 25 estiletes verticais com peso de 90 gramas, terminando com uma ponta de $1 \mathrm{~mm}$ de diâmetro.
Os estiletes ficam apoiados sob os grãos de feijão. O aparelho, com os 25 grãos, é colocado dentro de uma panela com água destilada fervente (temperatura padronizada de $95^{\circ} \mathrm{C}$ ) e na medida em que ocorre o cozimento, os estiletes perfuram os grãos. O tempo de cocção em minutos foi determinado a partir da queda dos 13 primeiros estiletes de um total de 25 hastes que perfuram os grãos de feijão $(50 \%+1)$.

Os dados foram submetidos à análise de variância pelo teste $F$ ao nível de $5 \%$ de probabilidade de erro, para testar as hipóteses dos efeitos principais e da interação entre os fatores. Quando o efeito da interação foi significativo, os graus de liberdade foram desdobrados, através do efeito simples, e posteriormente foram ajustadas equações de regressão para os fatores do tipo quantitativo, através do programa estatístico $\mathrm{SAS}^{\circledR}$, versão 2.0 (SAS INSTITUTE, 2004).

\section{Resultados e Discussão}

A análise de variância para o caráter tempo de cocção revelou diferenças significativas para a interação tripla genótipo versus armazenamento versus recobrimento (Tabela 1).

As comparações entre tratamentos podem ser afetadas substancialmente pelas condições em que ocorrem, e, interpretações claras dos efeitos de um tratamento precisam ser levadas em conta para o efeito de outros tratamentos (KUEHL, 1994). Freqüentemente a interação entre fatores pode estar presente em tais delineamentos e, sendo o efeito da interação significativa, é necessário fazer um estudo dessa interação por meio de composição em fatores aninhados (NOGUEIRA; CORRENTE, 2000). Desse modo, para as interações, onde os efeitos foram significativos, os graus de liberdade foram desdobrados através do efeito simples, fixando dois fatores e variando o outro (Tabela 1). Pois este procedimento conduz ao conhecimento detalhado do efeito de um fator, quando os outros são mantidos constantes (HINKELMANN; KEMPTHORNE, 1994). Observando ainda a mesma tabela, como o 
efeito da interação tripla entre os fatores (genótipos recobrimento. De modo que para a determinação $\mathrm{x}$ armazenamento $\mathrm{x}$ recobrimento) foi significativo, do grau dos polinômios linear e quadrático, de o procedimento indicado deve ser ajustar uma acordo com a significância pelo teste $F$, foi ajustada equação de regressão linear simples para cada nível do fator genótipo em cada nível do fator a equação de regressão separadamente para cada genótipo em cada polímero testado (Figura 1).

Tabela 1. Resumo da análise de variância, decomposição da interação tripla $\left(G^{*} A^{*} R\right)$ e teste de significância dos componentes linear e quadrático indicando graus de liberdade e os quadrados médios para a variável resposta tempo de cocção em minutos em dois genótipos de feijão sendo um do grupo preto (IPR-Uirapuru) e um do grupo carioca (Pérola) com três níveis de recobrimento (sem recobrimento, polímero CMC e polímero CMC-AS) avaliados em três datas de armazenamento ( 0,45 e 90 dias).

\begin{tabular}{|c|c|c|c|}
\hline & Fontes de Variação & Graus de Liberdade & Quadrado Médio \\
\hline \multirow{8}{*}{ 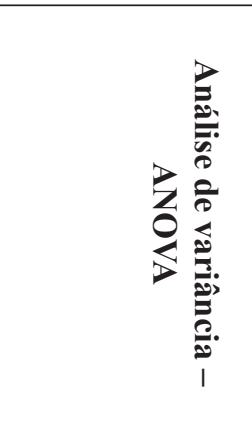 } & Bloco & 2 & ${ }^{\mathrm{ns}} 6,30$ \\
\hline & Genótipos (G) & 1 & ${ }^{*} 208,40$ \\
\hline & Armazenamento (A) & 2 & *230,60 \\
\hline & Recobrimento (R) & 2 & ${ }^{\mathrm{n} s} 12,60$ \\
\hline & $\mathrm{G}^{*} \mathrm{~A}$ & 2 & *31,10 \\
\hline & $\mathrm{G} * \mathrm{R}$ & 2 & ${ }^{\mathrm{ns}} 1,30$ \\
\hline & $\mathrm{A} * \mathrm{R}$ & 3 & *22,10 \\
\hline & $\mathrm{G}^{*} \mathrm{~A} * \mathrm{R}$ & 3 & *28,30 \\
\hline \multirow{6}{*}{ 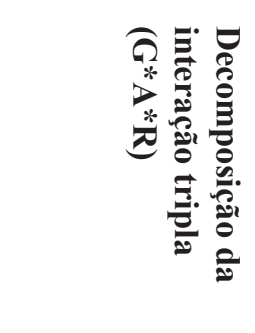 } & $\mathrm{A}\left|\mathrm{G}_{1}\right| \mathrm{R}_{1}$ & 1 & ${ }^{\mathrm{ns}} 0,67$ \\
\hline & $\mathrm{A}\left|\mathrm{G}_{1}\right| \mathrm{R}_{2}$ & 2 & $* 41,33$ \\
\hline & $\mathrm{A}\left|\mathrm{G}_{1}\right| \mathrm{R}_{3}$ & 2 & *40,11 \\
\hline & $\mathrm{A}\left|\mathrm{G}_{2}\right| \mathrm{R}_{1}$ & 1 & ${ }^{*} 160,17$ \\
\hline & $\mathrm{A}\left|\mathrm{G}_{2}\right| \mathrm{R}_{2}$ & 2 & *112,11 \\
\hline & $\mathrm{A}\left|\mathrm{G}_{2}\right| \mathrm{R}_{3}$ & 2 & * 48,44 \\
\hline \multirow{12}{*}{ 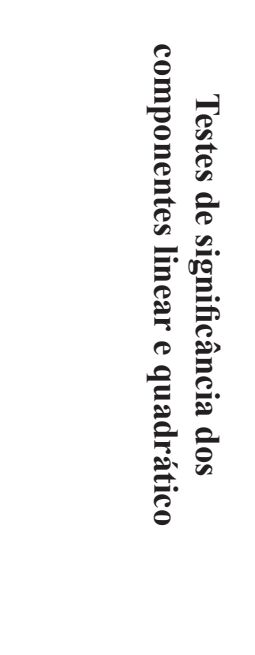 } & $\mathrm{A}_{2} v s \cdot \mathrm{A}_{1} \mid \mathrm{G}_{1}$ & 1 & ${ }^{\mathrm{ns}} 0,67$ \\
\hline & A linear $\left|\mathrm{R}_{2}\right| \mathrm{G}_{1}$ & 1 & ns 32,67 \\
\hline & A quadrático $\left|\mathrm{R}_{2}\right| \mathrm{G}_{1}$ & 1 & ${ }^{*} 50,00$ \\
\hline & A linear $\left|R_{3}\right| G_{1}$ & 1 & $* 73,50$ \\
\hline & A quadrático $\left|\mathrm{R}_{3}\right| \mathrm{G}_{1}$ & 1 & ${ }^{\mathrm{ns}} 6,72$ \\
\hline & $\mathrm{A}_{2} v s \cdot \mathrm{A}_{1} \mid \mathrm{G}_{2}$ & 1 & ${ }^{*} 121,50$ \\
\hline & A linear $\left|R_{2}\right| G_{2}$ & 1 & *204,17 \\
\hline & A quadrático $\left|\mathrm{R}_{2}\right| \mathrm{G}_{2}$ & 1 & ns 20,06 \\
\hline & A linear $\left|R_{3}\right| G_{2}$ & 1 & ${ }^{*} 96,00$ \\
\hline & A quadrático $\left|\mathrm{R}_{3}\right| \mathrm{G}_{2}$ & 1 & ${ }^{\mathrm{n}} 0,89$ \\
\hline & Erro & 30 & 7,9 \\
\hline & Total & 47 & \\
\hline \multicolumn{2}{|c|}{$\mathrm{R}^{2}$} & 0,81 & \\
\hline \multicolumn{2}{|c|}{ Coeficiente variação (\%) } & 8,27 & \\
\hline \multicolumn{2}{|c|}{ Média geral (minutos) } & 34,10 & \\
\hline
\end{tabular}

${ }^{*}=\mathrm{P}<0,05$ de probabilidade pelo teste $F ;{ }^{\text {ns }}=\mathrm{P}>0,05$ não significativo 


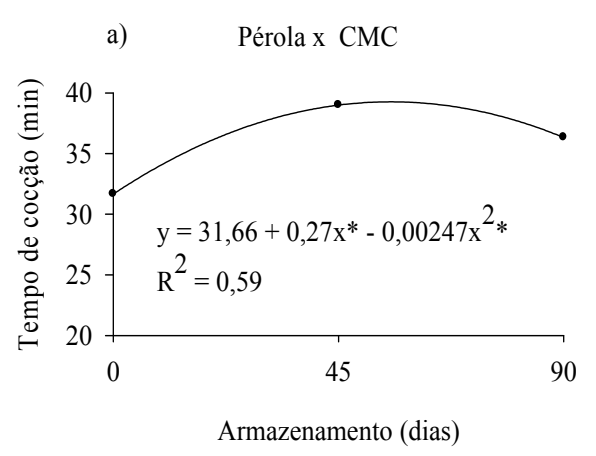

c) Pérola $\mathrm{x}$ CMC-AS

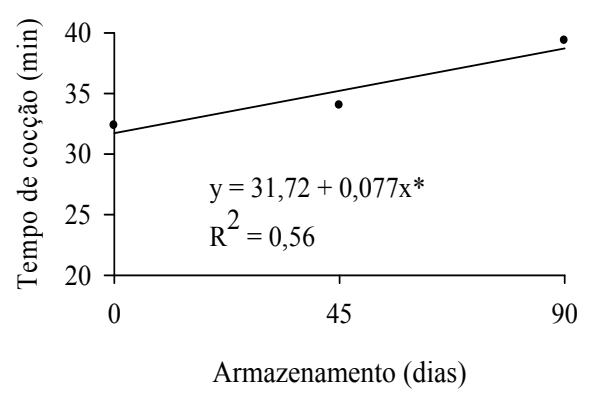

b) IPR-Uirapuru $\mathrm{x}$ CMC

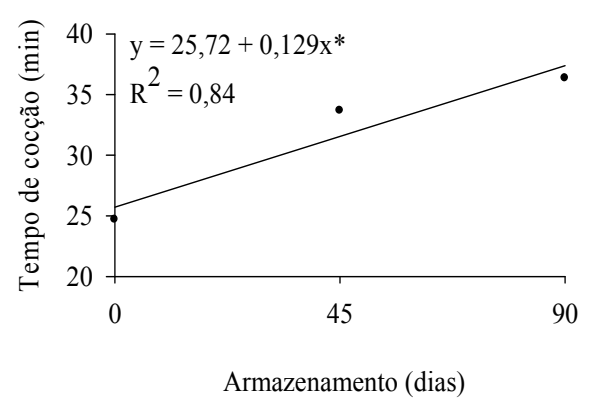

d) IPR-Uirapuru x CMC-AS

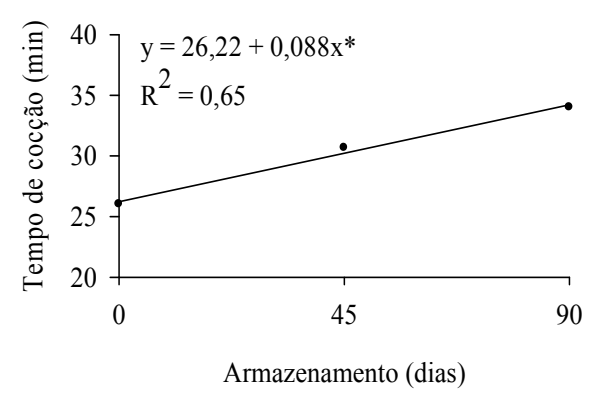

Figura 1. Comportamento dos genótipos Pérola e IPR-Uirapuru revestidos com os diferentes polímeros Carboximetilcelulose (CMC) e Carboximetilcelulose / Alginato de sódio (CMC-AS) ao longo do armazenamento para o tempo de cocção: a) Pérola x CMC; b) IPR-Uirapuru x CMC; c) Pérola x CMC-AS e; d) IPR-Uirapuru x CMCAS.

De modo geral, os resultados indicam que durante o período de armazenamento, o tempo de cozimento dos grãos aumentou. O tempo de cozimento em grãos de feijão é influenciado por diversos fatores, sejam de ambiente e/ou fisiológicos, como, por exemplo: i) o tempo de armazenamento; ii) a interação entre genótipo e ambiente e; iii) o tempo necessário para a máxima hidratação. Um dos aspectos que influenciam o aumento no tempo de cocção é o endurecimento do tegumento do grão, propiciado com o passar dos dias de armazenagem, onde segundo Jackson e Varriano-Marston (1981), Garcia e Lajolo, (1994), o armazenamento prolongado e inadequado a altas temperaturas e umidade relativa (UR) promove a degradação da membrana, reduzindo o valor nutricional e provocando alterações na qualidade sensorial. Durante o armazenamento ocorrem mudanças gradativas tanto físicas quanto químicas nos grãos, como o escurecimento do tegumento, endurecimento, perda da capacidade de re-hidratação, mudanças no sabor, e principalmente o tempo de cozimento.

Segundo Rios, Abreu e Corrêa (2003) a qualidade culinária do feijão é consideravelmente afetada à medida que se aumentam os meses de armazenamento. Com relação aos efeitos na qualidade dos grãos, durante o armazenamento prolongado, ocorrem dois fenômenos relacionados: i) hardshell e; ii) hard-to-cook. O termo "hardshell" se refere às sementes maduras e secas, que falham em absorver água quando embebidas em períodos relativamente longos (BOURNE, 1967); quando as condições de estocagem são de $40^{\circ} \mathrm{C}$ e umidade relativa de $80 \%$, o nitrogênio da parede celular e a hemicelulose se transferem da casca para o 
cotilédone no feijão comum, ocorrendo mudanças físicas e químicas nos cotilédones e a níveis intercelulares durante o armazenamento, resultando num aumento na estabilidade da lamela média ocorrendo o efeito "hard-to-cook" fazendo com que haja o endurecimento dos grãos para a cocção (ROZO; BOURNE; HOOD, 1990; KIGEL, 1999). Ainda, segundo Bourne (1967) "hard-to-cook" está associado ao não-amolecimento do cotilédone durante a cocção, mesmo que a semente absorva água e "hardshell" caracteriza impermeabilidade do tegumento à água que impede a reidratação dos grãos, pois conforme Sgarbieri (1987) "hardshell” é favorecido pela baixa umidade relativa na atmosfera e pelo alto teor de água nos grãos.

Para o tratamento sem recobrimento $(\mathrm{r}=0)$ não foram ajustadas equações de regressão, sendo os graus de liberdade igual a um (1). Diferenças significativas foram observadas para o genótipo IPR-Uirapuru com o tempo de cocção aumentando de 30,33 minutos (45 dias) para 40,66 minutos ( 90 dias). De acordo com os resultados, para o genótipo Pérola recoberto com o CMC (a), o ponto de máxima foi aos 54 dias de armazenamento, com um tempo de cocção de 39 minutos, decrescendo após esse período. Para o genótipo IPR-Uirapuru recoberto com o CMC (b), pode se observar que o tempo de cozimento foi de 25,7 minutos sem armazenagem, aumentando 6 minutos nos 45 dias de armazenamento (31,5 minutos) e aos 90 dias, o aumento foi de 11 minutos (37,3 minutos). O genótipo Pérola para o recobrimento com o CMC-AS (c) teve como tempo de cocção inicial de 32,3 minutos, aumentando aos 45 dias de armazenamento 3,5 minutos (35 minutos) e 7 minutos (39 minutos) após 90 dias de armazenamento. Com relação ao recobrimento do genótipo IPR-Uirapuru com o CMC-AS (d), a partir de 26,2 minutos sem armazenamento houve um acréscimo de 4 minutos no tempo de cocção aos 45 dias de armazenamento houve um acréscimo de 4 minutos no tempo de cocção aos 45 dias de armazenamento (30 minutos) e 8 minutos aos 90 dias (34 minutos) (Figura 1).
Os resultados revelam comportamentos diferenciados entre os genótipos avaliados recobertos com os diferentes polímeros testados. $\mathrm{O}$ comportamento do genótipo Pérola recoberto com o CMC (a) foi quadrático, ou seja, até 54,7 dias de armazenamento o caráter tempo de cocção cresce linearmente, sendo provavelmente estabilizado após esta data de armazenamento. Para o mesmo genótipo, porém recoberto com o CMC-AS (c), o comportamento foi nitidamente linear, sendo que o incremento (coeficiente de regressão) no tempo de cocção foi menor do que os tratamentos com o genótipo IPR-Uirapuru CMC-AS (b) e IPRUirapuru CMC (d) (3,1 $\mathrm{min}, 3,9 \mathrm{~min}$ e 5,4 $\mathrm{min}$ respectivamente), sendo que todos evidenciaram um comportamento linear.

Segundo Paula, Ramalho e Abreu (2004) há evidências de diferenças genéticas entre as linhagens do feijoeiro quanto ao tempo de cocção. Avaliando a variabilidade de grãos de feijão do Banco de Germoplasma da Universidade Federal de Lavras (UFLA) para a absorção de água, Costa, Ramalho e Abreu (2001) verificaram diferenças significativas entre as linhagens, sendo um indicativo de que elas diferem quanto às propriedades culinárias, especialmente tempo de cozimento, devido à correlação existente com a capacidade de hidratação. A variabilidade existente entre as cultivares quanto ao tempo de cocção, pode estar associada a diferenças de substâncias presentes nos grãos, como por exemplo, lignina. As diferenças têm sido correlacionadas à presença de algumas substâncias no grão, com os teores mais elevados de polifenóis, lignina e maiores atividades das enzimas peroxidase e polifenoloxidase, todos responsáveis pelo maior tempo de cocção (ESTEVES et al., 2002). De acordo com estes mesmos autores há diferenças significativas entre as linhagens para o teor de lignina. Segundo Reyes-Moreno e Paredes-López (1993), o fenômeno do hard-to-cook está relacionado com a lignificação da lamela média. A lignificação das membranas celulares lhes proporciona uma considerável resistência e rigidez, nesse caso, para 
os genótipos estudados, as diferenças no tempo de cocção podem estar relacionadas com uma maior presença de lignina, aumentando a rigidez das membranas dos cotilédones, determinando, assim, um aumento no tempo de cocção.

Os resultados obtidos podem indicar que o recobrimentodegrãos defeijãopodeserumaestratégia vantajosa dentro de programas de melhoramento de cultivares, uma vez que, os polímeros utilizados são incolores, inodoros, solúveis em água, não prejudicam a saúde e são economicamente viáveis. O revestimento proporciona uma cobertura durável, permeável à água, com a possibilidade de aplicação em sementes de diferentes formas e tamanhos, sem afetar seu processo germinativo (BACON; CLAYTON, 1986).

Apesar da importância em se recobrir grãos com polímeros, existe pouca informação sobre o revestimento, desde os próprios polímeros a serem utilizados bem como a sua respectiva composição, até a tecnologia adequada ao tratamento de grandes volumes. Para muitas espécies de sementes o processo de recobrimento pode ser aplicado, com uma melhoria na qualidade das sementes e na manutenção das propriedades de armazenamento (ALMEIDA; ROCHA; RAZERA, 2005). Dentre essas propriedades de armazenamento, os polímeros podem ajudar na redução da taxa de respiração aeróbia da semente, propiciando um maior tempo de armazenagem sem prejudicar características culinárias, como por exemplo, o tempo de cocção. De acordo com Duan e Burris (1997), os polímeros utilizados na peliculização podem restringir a entrada de água e ou oxigênio pela semente. Neste sentido, Sachs, Cantliffe e Nell (1981) relatam que a maioria dos materiais de revestimento utilizados dificulta a penetração de oxigênio na semente, e a maior resistência está na granulometria do material.

Assim, existem diferenças entre os materiais no recobrimento, onde dependendo do material utilizado, melhores resultados podem ser obtidos. A resposta para materiais de recobrimento depende muito das características de cada espécie, como também dos materiais utilizados para a peliculização (TRENTINI et al., 2005). Rivas, Gee e Burris (1998) estudando diferentes polímeros (Sacrust, Chitosan, Daran e Certop) aplicados sobre sementes de milho, não encontraram diferenças significativas entre eles, sobre a qualidade de sementes.

Contudo, a associação de características tecnológicas aliadas às culinárias é de suma importância no desenvolvimento de grãos com menor tempo de cocção e possivelmente com redução nos danos causados por fungos durante o armazenamento, uma vez sendo o polímero associado ao recobrimento com algum fungicida. A peliculização é uma tecnologia que permite, dentre outros usos, a adição de agroquímicos às sementes, sem mudanças no tamanho ou forma das mesmas (TRENTINI et al., 2005). Ainda, segundo Trentini et al. (2005), as películas além de serem utilizadas como materiais que ajudam a manter os produtos químicos fixados às sementes de maneira uniforme, também contribuem para uma melhoria no desempenho germinativo destas principalmente quando expostas às condições desfavoráveis que prejudicam o processo de germinação. Além disso, há também, possibilidade de inclusão de produtos como: pequenas quantidades de nutrientes, reguladores de crescimento e inoculantes e também como veículo para aplicação de inseticidas, fungicidas e repelentes de pássaros (SILVA; NAKAGAWA, 1998).

\section{Conclusão}

O recobrimento dos grãos de feijão com os polímeros ao longo do armazenamento apresenta comportamentos diferenciados para o caráter tempo de cocção.

O recobrimento com o polímero Carboximetilcelulose para o genótipo Pérola reduz o tempo de cocção durante o armazenamento significativamente.

A peletização dos grãos do genótipo Pérola 
com a mistura dos polímeros Carboximetilcelulose e Alginato de sódio (CMC-AS) promove menor variação no caráter tempo de cocção ao longo do armazenamento.

\section{Agradecimentos}

Agradecemos à UDESC, UFSC, CNPq, CAPES e FAPESC, pela concessão de bolsa e apoio financeiro.

\section{Referências}

ALMEIDA, C.; ROCHA, S. C. S.; RAZERA. L. F. Polymer coating, germination and vigor of broccoli seeds. Scientia Agricola, Piracicaba, v. 62, n. 3, p. 221226, 2005.

BACON, J. R.; CLAYTON, P. B. Protection for seeds: a new film coating technique. Span, Derby, v. 29, n. 2, p. 54-56, 1986.

BOURNE, M. C. Size density and hardshell in dry beans. Journal of Food Technology, Chicago, v. 21, n. 1, p. 1720, 1967.

CARBONELL, S. A. M.; CARVAlHO, C. R. L.; PEREIRA, V. R. Qualidade tecnológica de grãos de genótipos de feijoeiro cultivados em diferentes ambientes. Bragantia, Campinas, v. 62, n. 3, p. 369-379, 2003.

COIMBRA, J. L. M.; SOUZA, V. Q.; KOOP, M. M.; SILVA, J. G. C.; OLIVEIRA, A. C.; CARVALHO, F. I. F. Esperanças matemáticas dos quadrados médios: uma análise essencial. Ciência Rural, Santa Maria, v. 36, n. 6, p. 1730-1738, 2006.

COSTA, G. R.; RAMALHO, M. A. P.; ABREU, E. F. B. Variabilidade para absorção de água nos grãos de feijão do germoplasma da UFLA. Ciência e Agrotecnologia, Lavras, v. 25, n. 4, p. 1017-1021, 2001.

DUAN, X.; BURRIS, J. S. Film coating impairs leaching of germination inhibitors in sugar beet seed. Crop Science, Madison, v. 37, n. 22, p. 515-520, 1997.

ESTEVES, A. M.; ABREU, C. M. P.; SANTOS, C. D.; CORREAA, A. D. Comparação química e enzimática de seis linhagens de feijão (Phaseolus vulgaris L.). Ciência e Agrotecnologia, Lavras, v. 26, n. 5, p. 999-1005, 2002.

FERREIRA, C. M.; DEL PELOSO, M. J.; FARIA, L. C. Feijão na economia nacional. Santo Antônio de Goiás: Embrapa Arroz e Feijão, 2002. 47 p. (Documentos, 135).
FOOD AND AGRICULTURE ORGANIZATION - FAO. Base de dados FAOSTAT. Rome: FAO, 2006. Disponível em: $<$ http://www.apps.fao.org>. Acesso em: 10 jun. 2007.

GARCIA, E.; LAJOLO, F. M. Starch alterations in hardto-cook beans (Phaseolus vulgaris L.). Journal of Agricultural and Food Chemistry, Washington, v. 42, n. 3, p. 612-615, 1994.

HINKELMANN, K.; KEMPTHORNE, O. Design and analysis of experiments: introduction to experimental design. New York: JohnWiley \& Sons, 1994. v. 1, 495 p.

IBGE. Instituto Brasileiro de Geografia e Estatística. Levantamento sistemático da produção agrícola: pesquisa mensal de previsão e acompanhamento das safras agrícolas no ano civil - dezembro de 2009. Rio de Janeiro: IBGE, 2009. Disponível em: <http://www.ibge. gov.br/home/estatistica/ indicadores/agropecuaria/lspa>. Acesso em: 26 fev. 2010.

JACKSON, M. G.; VARRIANO-MARSTON, E. Hardto-cook phenomenon in beans: effects of ccelerated storage on water absorption and cooking time. Journal of Food Science, Chicago, v. 46, n. 3, p. 799-803, 1981.

KIGEL, J. Culinary and nutritional quality of Phaseolus vulgaris seeds as affected by evironmental factors. Biotechnologie Agronomie Society Enviroment, Jerusalém, v. 3, n. 4, p. 205-209, 1999.

KUEHL, R. O. Statistical principles of research design and analysis. Belmont, California: Duxbury Press, 1994. $686 \mathrm{p}$.

MINISTÉRIO DA AGRICULTURA, PECUÁRIA E ABASTECIMENTO - MAPA. Anexo IV. Brasília: Diário Oficial da União. 1998. Disponível em: <http://extranet. agricultura.gov.br/sislegisconsulta/ consultarLegislacao. do? operacao $=$ visualizar\&id $=15013>$. Acesso em: $26 \mathrm{fev}$. 2010.

MORRIS, H. J.; OSLON, R. L. Processing quality of varieties and strains of dry beans. Food Technology, Chicago, v. 4, n. 2, p. 247-251, 1950.

NI, B. R.; BIDDLE, A. J. Alleviation of seed imbibitional chilling injury using polymer film coating: seed treatment challenges and opportunities. British Crop Protection Council, Brunswick, v. 13, n. 1, p. 73-80, 2001.

NOGUEIRA, M. C. S.; CORRENTE, J. E. Decomposição da interação tripla significativa utilizando o comando contrats do PROC GLM do SAS aplicado ao modelo de classificação tripla para dados balanceados. Bragantia, Campinas, v. 59, n. 1, p. 109-115, 2000.

OLIVEIRA, J. A.; PEREIRA, C. E.; GUIMARÃES, R. M.; VIEIRA, A. R.; SILVA, J. B. C. Efeito de diferentes materiais de peletização na deterioração de sementes de 
tomate durante o armazenamento. Revista Brasileira de Sementes, Londrina, v. 25, n. 2, p. 20-27, 2003.

PAULA, S. R. R.; RAMALHO, M. A. P.; ABREU, A. F. B. Effects of reciprocal crossing on the cooking time of dry bean. In: Annual report of the bean improvement cooperative, East Lansing, Michigan State University, n. 47, p. 223-224, 2004.

PIRES, L. L.; BRAGANTINI, C. Armazenamento de sementes de feijão revestidas com polímeros e tratadas com fungicidas. Pesquisa Agropecuária Brasileira, Brasília, v. 39, n. 7, p. 709-715, 2004.

PROCTOR, J. R.; WATTS, B. M. Development of a modified mattson bean cooker procedure based on sensory panel cookability evaluation. Canadian Institute of Food Science and Technology Journal, Apple Hill, v. 20, n. 1, p. 9-14, 1987.

REYES-MORENO, C.; PAREDES-LÓPEZ, O. Hard-tocook phenomenon in common beans - a rewiew. Critical Reviews in Food Science and Nutrition, Boca Raton, v. 33, n. 3, p. 227-286, 1993.

RIOS, A. O.; ABREU, C. M. P.; CORRÊA, A. D. Efeito da estocagem e das condições de colheita sobre algumas propriedades físicas, químicas e nutricionais de três cultivares de feijão (Phaseolus vulgaris, 1.). Ciência e Tecnologia de Alimentos, Campinas, v. 23, p. 39-45, 2003. Suplemento.

RIVAS, B. A.; GEE, D. C.; BURRIS, J. S. Tratamiento de semillas de maiz con polimeros para el control de Pythium spp. Fitopatologia Venezuelana, Caracas, v. 11, n. 1, p. 10-15, 1998.
ROOS, E. E.; MOORE, F. D. Effect of seed coating performance of lettuce seeds in greenhouse soil tests. Journal American Society Horticultural Science, Alexandria, v. 100, n. 5, p. 573-576, 1975.

ROZO, C.; BOURNE, M. C.; HOOD, L. F. Effect of storage time, relative humidity and temperature on the cookability of whole red kidney beans and on the cell wall components of the cotyledons. Canadian Institute Food Science Technology, Ottawa, v. 23, n. 1, p. 72-75, 1990.

SACHS, M.; CANTLIFFE, D. J.; NELL, T. A. Germination studies of clay-coated sweet pepper seeds. Journal American Society Horticultural Science, Alexandria, v. 106, n. 26, p. 385-389, 1981.

SAS INSTITUTE. SAS certification prep guide: base programming. Cary, North Carolina, USA, 2004. v. 6, $836 \mathrm{p}$.

SGARBIERI, V. C. Alimentação e nutrição: fator de saúde e desenvolvimento. Campinas: Unicamp, Almed, 1987. $387 \mathrm{p}$.

SILVA, J. B. C.; NAKAGAWA, J. Confecção e avaliação de péletes de sementes de alface, Horticultura Brasileira, Brasília, v. 16, n. 2, p. 151-158, 1998.

TRENTINI, P.; GUIMARÃES, M. G.; VIEIRA, C.; CARVALHO, M. L. M.; OLIVEIRA, J. A.; MACHADO, J. C. Peliculização: desempenho de sementes de soja no estabelecimento da cultura em campo na região de alto garças, MT. Ciência e Agrotecnologia, Lavras, v. 29, n. 1, p. 84-92, 2005. 